\title{
Meta-analysis-based systematic review of effect of traditional Chinese medicine intervention in treatment of diabetic nephropathy on thyroid function
}

\author{
Xinxia Zhang ${ }^{1}$, Mengzhu Wu ${ }^{1}$, Jun Zhou ${ }^{1}$, Rong Zhou ${ }^{1}$, Qiaocui Luo ${ }^{1}$, Rensong Yue ${ }^{1}$, Shuoguo Jin ${ }^{2}$ \\ ${ }^{1}$ Department of Endocrinology, Hospital of Chengdu University of Traditional Chinese Medicine, Chengdu, China; ${ }^{2}$ Department of Neurology, \\ Hospital of Chengdu University of Traditional Chinese Medicine, Chengdu, China \\ Contributions: (I) Conception and design: X Zhang, R Yue, S Jin; (II) Administrative support: M Wu, J Zhou; (III) Provision of study materials or \\ patients: X Zhang, M Wu, J Zhou, R Zhou, Q Luo; (IV) Collection and assembly of data: All authors; (V) Data analysis and interpretation: R Zhou, \\ Q Luo, R Yue, S Jin; (VI) Manuscript writing: All authors; (VII) Final approval of manuscript: All authors. \\ Correspondence to: Rensong Yue; Shuoguo Jin. Hospital of Chengdu University of Traditional Chinese Medicine, No. 39, Shi Er Qiao Road, Jinniu \\ District, Chengdu 610072, China. Email: yuerensong@hotmail.com; jinshuoguo@cdutcm.edu.cn.
}

\begin{abstract}
Background: This research sought to systematically evaluate the clinical effects of traditional Chinese medicine (TCM) intervention in the treatment of diabetic nephropathy (DN) and analyze changes in thyroid function in patients with DN.

Methods: The PubMed, Embase, Medline, Ovid, Springer, and self-built databases were searched to screen literature on TCM intervention and the treatment of DN published from the establishment of the databases to January 1, 2021. The Cochrane Handbook for Systematic Reviews of Intervention 5.0.2 was then employed to assess the risk of bias in literature, and Review Manager 5.3 was utilized for the meta-analysis.

Results: A total of 20 randomized controlled trials (RCTs) were included in the study, involving 3,566 subjects, and meta-analysis results showed that the clinical treatment efficiency of the experimental group was dramatically higher than the control group $[\mathrm{MD}=6.22,95 \%$ confidence interval (CI): 3.77-10.25, $\mathrm{Z}=7.17$, $\mathrm{P}<0.00001]$. Moreover, the serum creatinine (Scr), blood urea nitrogen (BUN), urine protein excretion rate (UAER), $24 \mathrm{~h}$ postoperative urine protein quantification, and tumor necrosis factor-alpha (TNF- $\alpha$ ) of patients after TCM intervention were all remarkably inferior to those of the control group as seen in the following results: $\mathrm{Scr}, \mathrm{MD}=-8.69,95 \% \mathrm{CI}:-9.92$ to $-7.47, \mathrm{Z}=13.94, \mathrm{P}<0.00001$; BUN, $\mathrm{MD}=-1.74,95 \%$ CI: -2.48 to $-1.00, Z=4.6, P<0.00001$; UAER, $M D=-26.16,95 \% \mathrm{CI}:-46.89$ to $-5.44, Z=2.47, \mathrm{P}=0.01 ; 24 \mathrm{~h}$ postoperative urine protein quantification, $\mathrm{MD}=-0.54,95 \% \mathrm{CI}:-0.68$ to $-0.4, \mathrm{Z}=7.4, \mathrm{P}<0.00001$; TNF- $\alpha$, $\mathrm{MD}=-5.3,95 \% \mathrm{CI}:-9.15$ to $-1.46, \mathrm{Z}=2.7, \mathrm{P}=0.007$; and high sensitivity C-reactive protein (hs-CRP), MD $=-1.34,95 \%$ CI: -1.9 to $-0.78, \mathrm{Z}=4.66, \mathrm{P}<0.00001$.
\end{abstract}

Discussion: TCM intervention in DN is effective in treating the clinical symptoms of patients with this disease and has ideal therapeutic effects.

Keywords: Traditional Chinese medicine (TCM); diabetic nephropathy (DN); thyroid function; meta-analysis

Submitted Apr 16, 2021. Accepted for publication Jun 02, 2021.

doi: 10.21037/apm-21-1220

View this article at: http://dx.doi.org/10.21037/apm-21-1220

\section{Introduction}

Diabetic nephropathy (DN) is one of the most serious complications of diabetes and its incidence in China is increasing. At present, in addition to various glomerulonephropathies, DN is one of the main causes of end-stage renal disease (1). The pathogenesis of DN has not yet been fully clarified, and it is currently believed to be the result of a variety of factors, including genetic factors, 
abnormal renal hemodynamics, and metabolic abnormalities caused by hyperglycemia (2). Due to this complexity, once it develops to end-stage renal disease, $\mathrm{DN}$ is often more difficult to treat than other kidney diseases. Therefore, timely prevention and treatment is of great significance for delaying the disease (3).

The current clinical treatment of DN varies according to different stages, and mainly involves the control of blood sugar and blood pressure. Treatment methods include drugs, equipment, diet control, and organ transplantation. During the treatment process, the patient must maintain a high degree of cooperation, follow medical advice, and comply with medication prescriptions. However, conventional western medical treatment has a variety of side effects including infections, and can place unsustainable demands on other organs (4). Traditional Chinese medicine (TCM) is a unique treatment method which has shown significant benefits in the treatment of many conditions including gynecological diseases and pediatric pneumonia. As DN is an autoimmune system disease, often accompanied by disorders of thyroid function, we sought to analyze the thyroid function of patients with DN and the treatment effect of TCM therapy on the disease. We present the following article in accordance with the PRISMA reporting checklist (available at http://dx.doi.org/10.21037/apm-21-1220).

\section{Methods}

\section{Literature inclusion and exclusion criteria}

The inclusion criteria were as follows: (I) the study subjects were diagnosed with $\mathrm{DN}$, and the course of disease was 5 10 years; (II) the research type was a randomized controlled trial (RCT) published in an English language database; (III) the patients had related clinical features of nephrotic syndrome accompanied by hypertension, and renal failure was likely to occur in the late stage; (IV) the study was not restricted by the type, age, and course of diabetes.

The exclusion criteria were as follows: (I) cohort studies, case reports, and other non-RCT studies; (II) the research subject was non-DN, or the research object was animals or cells; (III) the treatment method of the literature experimental group was not TCM treatment or combined TCM and Western medicine treatment; (IV) unpublished literature or non-English literature such as degree theses; (V) a trial involving patients with DN combined with other diseases; (VI) literature with incomplete research data or literature published repeatedly.

\section{Literature search}

The PubMed, Embase, Medline, Ovid, Springer, Cochrane Library, and Web of Sciences databases were searched to screen literature on TCM intervention and treatment of DN published from the establishment of the database to January 1, 2021. The search term was composed of subject words and free words, including "traditional Chinese medicine intervention treatment", "diabetic nephropathy", "thyroid function", and "renal function". Joint searches using the terms "and" or "or" were also used. Literature retrieval was conducted by two research institutes using independent back-to-back retrieval methods.

\section{Literature screening}

Two evaluators independently screened the literature. After the literature search, the bibliography of each article was imported into Note Express 3.2 literature manager to establish a literature database and duplicate literature was identified and removed. After preliminary screening, the title and abstract of each article was then manually screened to check inclusion and exclusion criteria. Following this, the full text of included articles was carefully read to further discriminate inclusion and exclusion criteria. Disagreement between evaluators was resolved through consultation, and in cases where this was not possible, a third evaluator was consulted.

\section{Data extraction}

The two evaluators independently utilized the selfdeveloped data extraction table to extract data that met the inclusion criteria and cross-examined them after the extraction. The extracted information in the literature that met the inclusion criteria were those with (I) title, first author (only one name was included), publication year, and publication journal; (II) age, gender, sample size, and baseline comparability of the research subjects; (III) intervention measures and control measures; (IV) outcome indicators, including clinical treatment effective rate, free triiodothyronine (FT3), free thyroxine (FT4), thyroidstimulating hormone (TSH), triiodothyronine (T3), glycosylated hemoglobin (HbAIC), thyroxine (T4), serum creatinine (Scr), urine protein excretion rate (UAER), tumor necrosis factor-alpha (TNF- $\alpha$ ), high sensitivity C-reactive protein (hs-CRP), blood urea nitrogen (BUN), and $24 \mathrm{~h}$ postoperative urine protein quantification. Disagreement 


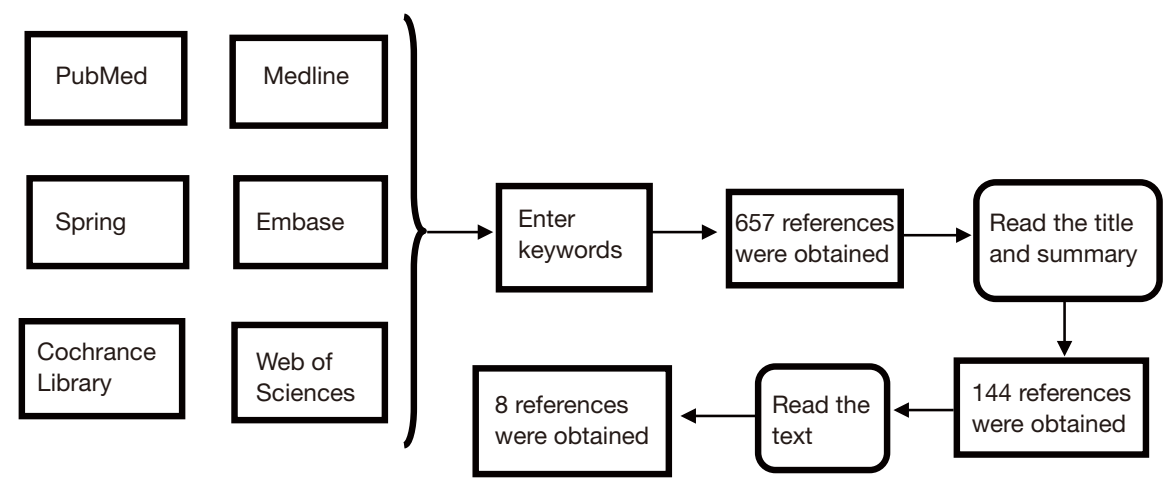

Figure 1 Literature retrieval process.

between evaluators was resolved through consultation, and in cases where this was not possible, a third evaluator was consulted.

\section{Bias risk assessment}

Using the Cochrane Handbook 5.0.2, the risk of bias assessment standard provided by the systematic review manual was adopted to evaluate the risk of bias of the original included literature. The evaluation criteria include selection bias, implementation bias, measurement bias, follow-up bias, and other biases. Specifically, it included whether it is a random sequence, whether there is allocate concealment, whether there is a blinding of the subjects, whether the blinding is implemented for the outcome assessor, whether the data is complete, whether there is selective reporting, and whether there are other biases. Disagreement between evaluators was resolved through consultation, and in cases where this was not possible, a third evaluator was consulted.

\section{Statistical analysis}

The bias analysis tool in the Cochrane Handbook for Systematic Reviews of Interventions 5.1.0 was employed to evaluate the risk of literature bias. STATA 12.0 was utilized to organize the data of the included literatures and Review Manager 5.3 was adopted for meta-analysis. If the measurement unit was not uniform between different samples, it was expressed in the form of standardized mean difference (SMD), and if it was found that the results of studies could be combined, a meta-analysis was performed. The combined effect size test used $u$ test and $95 \%$ confidence interval (CI), and the $u$ test result was expressed as $\mathrm{P}$ value. When $\mathrm{P}<0.05$, the difference was statistically significant. Binary variables took RR and $95 \%$ CI: as effect values, and continuous variables took SMD and $95 \% \mathrm{CI}$ : as effect values. According to heterogeneity $\left(\mathrm{I}^{2}\right)$, a fixed effects model (FEM) or random effects models (REM) was selected to analyze the combined effect size. Sensitivity analysis was performed to test whether the meta-analysis results were stable, and to explore the source of heterogeneity. If the source of heterogeneity was found, FEM was adopted for meta-analysis, and if not, REM was adopted. If metaanalysis was not possible (data research was less than two), descriptive analysis was performed. The final analysis result was defined as $\mathrm{P}<0.05$ with statistical difference.

\section{Results}

\section{Meta-analysis of thyroid function in patients with DN}

\section{Literature search results}

The corresponding keywords were searched in the six English databases and a total of 1,361 related articles were retrieved (Figure 1). Of these, 416 were from PubMed, 275 from Embase, 103 from Medline, 221 from Spring, 74 from Cochrane Library, and 272 from the Web of Science databases. After the preliminary search, Endnote X8 was firstly employed to eliminate duplicate articles and resulted in the exclusion of 657 articles. The two evaluators then excluded a further 513 articles based on examination of the title and abstract. The remaining 144 articles were read in full, resulting in eight articles which met the inclusion criteria. The eight articles included a total of 2,595 study subjects, including 993 patients allocated to an observation group and 1,602 patients to a control group. The basic characteristics of the studies in the included articles is 
Table 1 Basic characteristics of the studies included

\begin{tabular}{|c|c|c|c|c|}
\hline First author & Published year & Group & Sample size & Gender \\
\hline Zhang L (5) & & Control & 45 & \\
\hline \multirow[t]{2}{*}{ Han J (6) } & 2015 & Experimental & 40 & - \\
\hline & & Control & 40 & \\
\hline Jin JH (7) & & Control & 40 & 321; +19 \\
\hline \multirow[t]{2}{*}{ Gao HB (8) } & 2017 & Experimental & 33 & - \\
\hline & & Control & 1217 & \\
\hline Tan ZM (9) & 2018 & Experimental & 67 & $36 ;$ \\
\hline Duan SL (10) & & Control & 45 & \\
\hline \multirow[t]{2}{*}{ Yang N (11) } & 2017 & Experimental & 409 & J232; 우177 \\
\hline & & Control & 85 & $339 ;$ \\
\hline \multirow[t]{2}{*}{ Guo F (12) } & 2016 & Experimental & 295 & 194; 우101 \\
\hline & & Control & 80 & 45; + 35 \\
\hline
\end{tabular}

shown in Table 1.

\section{Bias risk assessment of included literature}

The Cochrane Handbook 5.0.2 bias risk assessment tool was employed to evaluate the bias risk of the eight articles included in this study. The evaluation results were then input to the Review Manager 5.3 to generate a bias risk map which involved the following. (I) Random sequence generation. The method of selecting patients with $\mathrm{DN}$ as the observation group and healthy people as the control group was reported in all eight articles (5-12), suggesting low risk. (II) Allocation concealment. None of the eight articles mentioned whether blinding was used, indicating unclear risk. (III) Subjects blinding. None of the eight articles informed whether subjects were blinded, indicating unclear risk. (IV) Blinding of outcome assessor. None of the eight articles mentioned whether blinding of the outcome assessor was used, indicating unclear risk. (V) Data integrity. The outcome data of the eight articles was complete, indicating low risk. (VI) Selective report. None of the eight articles could be determined to be a selective report, indicating unclear risk. (VII) Other biases. Five articles $(5,8,9,11,12)$ had different numbers of subjects in the experimental group and control group, indicating high risk. For the other three articles $(6,7,10)$, it was uncertain whether there were other biases, suggesting unclear risk. The detailed results of this bias analysis are shown in Figures 2 and 3.

\section{HbAIC}

Three $(3,5,8)$ of the eight articles included in this study reported on HbAIC in patients with DN. Among these, a total of 572 cases were included, including 402 cases in observation groups and 170 cases in control groups. Analysis revealed there was heterogeneity between the observation group and control group $\left(\mathrm{I}^{2}=99 \%, \mathrm{P}<0.00001\right)$, so the REM was adopted for analysis. Figure 4 shows the combined effect size obtained by the meta-analysis shows is $\mathrm{MD}=2.92,95 \% \mathrm{CI}: 0.03-5.8, Z=1.98$, and $\mathrm{P}=0.05$. The diamond in the forest plot is on the right side of the vertical line, which indicates that the HbAIC level of DN patients is higher than that of the control group.

\section{FT3}

All eight (5-12) articles reported on FT3 in patients with DN. A total of 2,595 subjects were included, including 


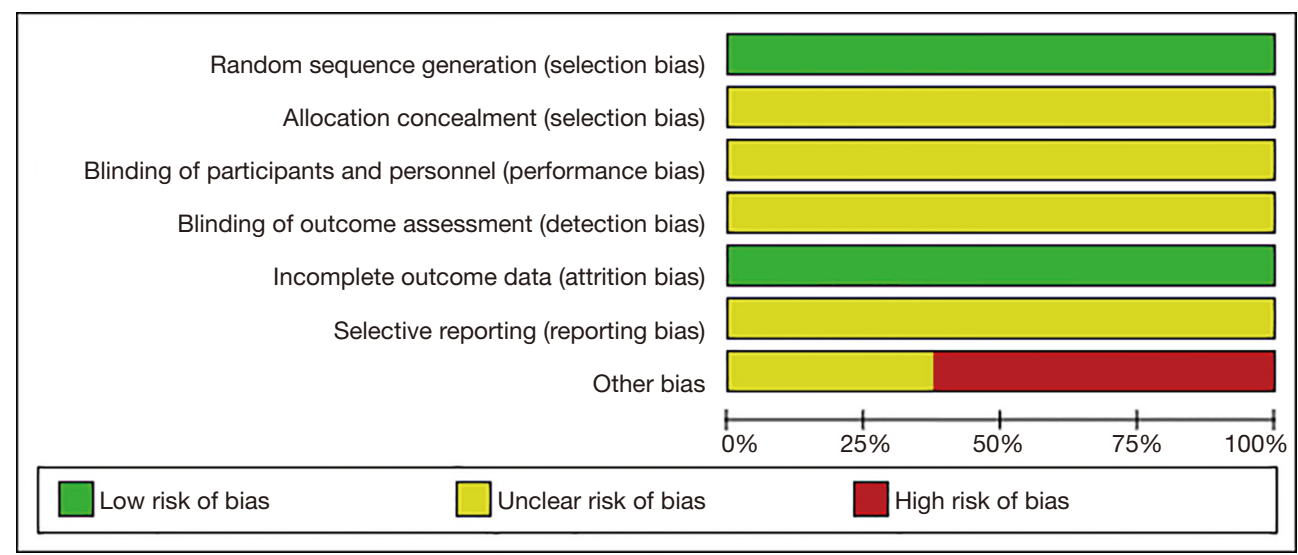

Figure 2 Bar graph of bias analysis of included literature.

\begin{tabular}{|c|c|c|c|c|c|c|c|c|}
\hline $\begin{array}{l}\text { N } \\
\text { ज्ञ } \\
0 \\
N \\
\text { O } \\
\text { N }\end{array}$ & 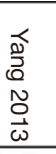 & \begin{tabular}{l}
$\vec{j}$ \\
\multirow{2}{*}{} \\
$N$ \\
$\stackrel{0}{\infty}$ \\
$\infty$
\end{tabular} & $\begin{array}{l}c \\
S \\
N \\
O \\
\text { ज }\end{array}$ & 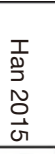 & $\begin{array}{l}\Omega \\
\text { ट } \\
\text { N } \\
\text { O } \\
\sigma \\
\end{array}$ & 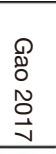 & 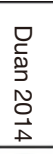 & \\
\hline$\oplus$ & + & $\oplus$ & + & + & + & + & + & Random sequence generation (selection bias) \\
\hline$\sim$ & $\sim$ & $\sim$ & $\sim$ & $\sim$ & $\sim$ & $\sim$ & $\sim$ & Allocation concealment (selection bias) \\
\hline$\sim$ & $\sim$ & $\sim$ & $\sim$ & $\sim$ & 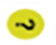 & $\sim$ & $\sim$ & Blinding of participants and personnel (performance bias) \\
\hline$\sim$ & $\sim$ & $\sim$ & $\sim$ & $\sim$ & $\sim$ & $\sim$ & $\sim$ & Blinding of outcome assessment (detection bias) \\
\hline+ & + & + & + & + & + & + & + & Incomplete outcome data (attrition bias) \\
\hline$\sim$ & $\sim$ & $\sim$ & $\sim$ & $\sim$ & $\sim$ & $\sim$ & $\sim$ & Selective reporting (reporting bias) \\
\hline (1) & (1) & 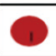 & $\sim$ & $\sim$ & D & (1) & $\sim$ & Other bias \\
\hline
\end{tabular}

Figure 3 Bias risk assessment diagram of included literature.

\begin{tabular}{|c|c|c|c|c|c|c|c|c|c|c|c|c|c|}
\hline Study or Subgroup & \multicolumn{3}{|c|}{ Experimental } & \multicolumn{2}{|c|}{ Control } & & \multicolumn{2}{|c|}{$\begin{array}{ll} & \text { Mean Difference } \\
\text { Weight } & \text { IV, Random, } 95 \% \mathrm{Cl}\end{array}$} & \multicolumn{3}{|c|}{$\begin{array}{c}\text { Mean Difference } \\
\text { IV. Random, } 95 \% \mathrm{CI}\end{array}$} & & \\
\hline Guo 2016 & 87 & 24 & 295 & 56 & 0.3 & 80 & $33.9 \%$ & $3.10[2823.381$ & & & - & & \\
\hline $\operatorname{Jin} 2015$ & 8.2 & 2 & 40 & 9 & 3 & 40 & $32.3 \%$ & $-0.80[-1.92,0.32]$ & & $-{ }^{-1}$ & & & \\
\hline Total $(95 \% \mathrm{Cl})$ & & & 402 & & & 170 & $100.0 \%$ & $2.92[0.03,5.80]$ & & & & & \\
\hline $\begin{array}{l}\text { Heterogeneity: } \mathrm{Tau}^{2}= \\
\text { Test for overall effect: }\end{array}$ & $\begin{array}{l}6.37 ; \mathrm{Cr} \\
\mathrm{Z}=1.98\end{array}$ & $\begin{array}{l}=23 \\
P=0\end{array}$ & $\begin{array}{l}9.41, d \\
.05)\end{array}$ & $f=2(F$ & $<0.00$ & $001) ; 1^{2}$ & $2=99 \%$ & & -10 & $\begin{array}{l}-5 \\
\text { oerimental] }\end{array}$ & 0 & & 10 \\
\hline
\end{tabular}

Figure 4 Forest plot of HbAIC of the two groups. HbAIC, glycosylated hemoglobin.

993 in observation groups and 1602 in control groups, and analysis revealed heterogeneity between the two was $\left(\mathrm{I}^{2}=94 \%, \mathrm{P}<0.00001\right)$. Therefore, the REM was adopted for analysis. Figure 5 shows the combined effect size obtained by the meta-analysis was $\mathrm{MD}=-0.64,95 \% \mathrm{CI}:-0.91$ to $-0.36, Z=4.46$, and $\mathrm{P}<0.00001$. The diamond in the forest plot is on the left side of the vertical line, which indicates that the FT3 level of DN patients is inferior to that of the control group.

\section{FT4}

Seven (5-11) of the eight articles reported on FT4 in 


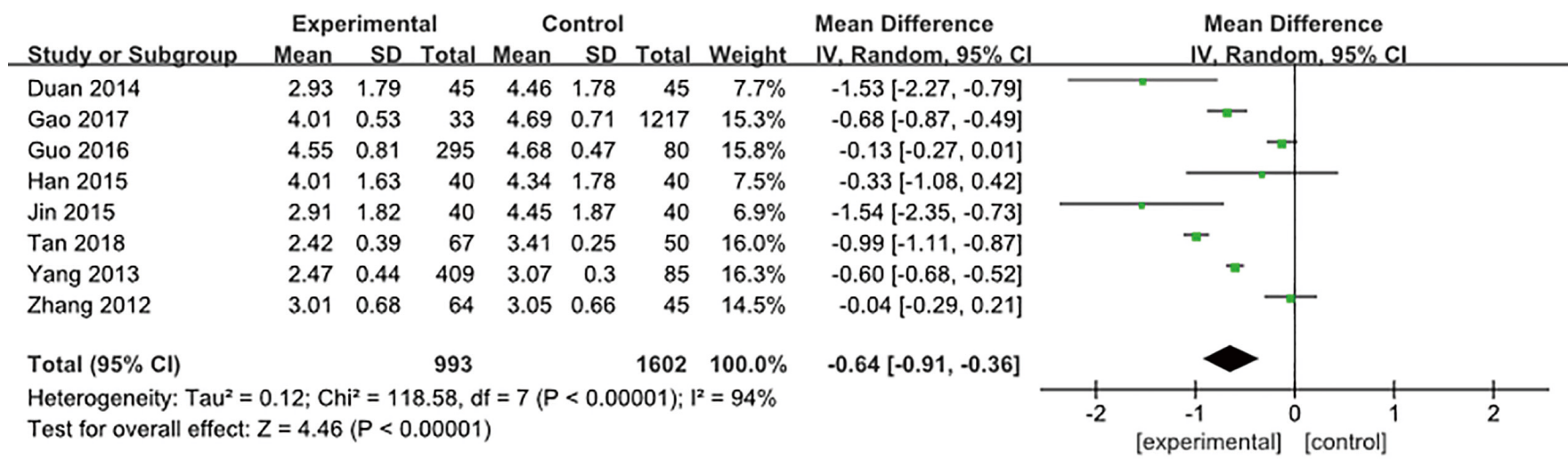

Figure 5 Forest plot of FT3 of the two groups. FT3, free triiodothyronine.

\begin{tabular}{|c|c|c|c|c|c|c|c|}
\hline \multirow[b]{2}{*}{ Study or Subgroup } & \multicolumn{3}{|c|}{ Experimental } & \multicolumn{2}{|c|}{ Control } & \multirow[b]{2}{*}{ Total } & \multirow[b]{2}{*}{ Weight } \\
\hline & Mean & $\mathrm{SD}$ & Total & Mean & SD & & \\
\hline Duan 2014 & 10.31 & 3.49 & 45 & 11.66 & 3.32 & 45 & $8.7 \%$ \\
\hline Gao 2017 & 14.97 & 2.46 & 33 & 17.31 & 2.58 & 1217 & $13.2 \%$ \\
\hline Han 2015 & 11.53 & 1.07 & 40 & 15.48 & 1.68 & 40 & $15.3 \%$ \\
\hline Jin 2015 & 10.3 & 3.5 & 40 & 11.64 & 3.3 & 40 & $8.2 \%$ \\
\hline Tan 2018 & 0.57 & 0.14 & 67 & 0.81 & 0.16 & 50 & $18.6 \%$ \\
\hline Yang 2013 & 11.7 & 1.7 & 409 & 11.6 & 1.4 & 85 & $17.5 \%$ \\
\hline Zhang 2012 & 1.3 & 0.35 & 64 & 1.39 & 0.45 & 45 & $18.4 \%$ \\
\hline Total $(95 \% \mathrm{Cl})$ & & & 698 & & & 1522 & $100.0 \%$ \\
\hline
\end{tabular}

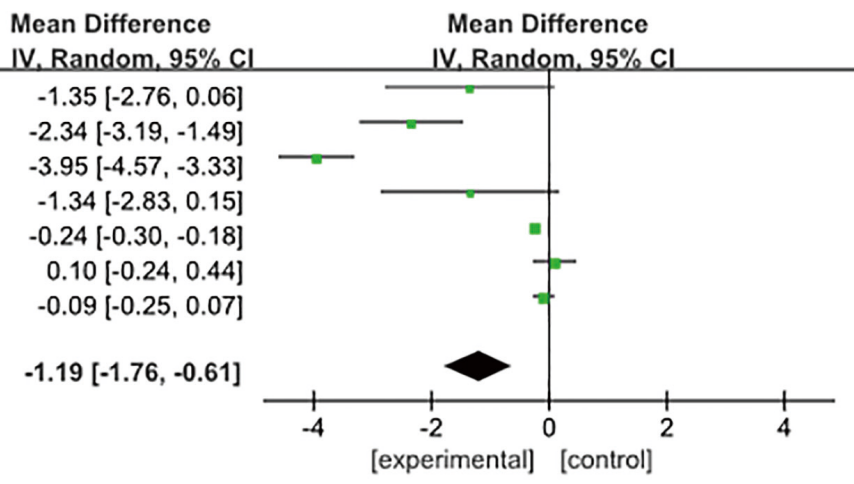

Figure 6 Forest plot of FT4 of the two groups. FT4, free thyroxine.

patients with DN. Among these, 2,220 cases were included, including 698 cases in observation groups and 1,522 cases in control groups. Analysis revealed heterogeneity between the groups $\left(\mathrm{I}^{2}=97 \%, \mathrm{P}<0.00001\right)$, the REM was adopted for analysis. Figure 6 shows the combined effect size obtained by the meta-analysis is $\mathrm{MD}=-1.19,95 \% \mathrm{CI}:-1.76$ to -0.61 , $Z=4.07$, and $\mathrm{P}<0.0001$. The diamond in the forest plot is on the left side of the vertical line, which indicates that the FT4 level of DN patients is inferior to that of the control group.

\section{TSH}

Seven of the eight articles (5-11) reported on TSH in patients with DN. Of these, 2,220 cases were included, including 698 cases in an observation group and 1,522 cases in a control group, and analysis revealed heterogeneity between the two groups $\left(\mathrm{I}^{2}=97 \%, \mathrm{P}<0.00001\right)$. Therefore, the REM was adopted for analysis. Figure 7 shows the combined effect size obtained by the meta-analysis was
MD $=1.06,95 \% \mathrm{CI}: 0.24-1.88, Z=2.54$, and $\mathrm{P}=0.01$. The diamond in the forest plot is on the right side of the vertical line, which indicates that the TSH level of DN patients is higher than that of the control group.

\section{T3}

Four of the eight articles $(6,7,10,12)$ reported on $\mathrm{T} 3$ in patients with DN and included 625 subjects with 420 in observation groups and 205 in control groups. As analysis showed heterogeneity between observation and control groups $\left(\mathrm{I}^{2}=96 \%, \mathrm{P}<0.00001\right)$, the REM was adopted for analysis. Figure 8 shows the combined effect size obtained by the meta-analysis is $\mathrm{MD}=-0.23,95 \% \mathrm{CI}:-0.49$ to 0.02 , $Z=1.82$, and $\mathrm{P}=0.07$. The diamond in the forest plot is on the left side of the vertical line, which indicates that the T3 level of DN patients is inferior to that of the control group.

T4

Three $(6,7,10)$ of the eight articles reported on $\mathrm{T} 4$ in 


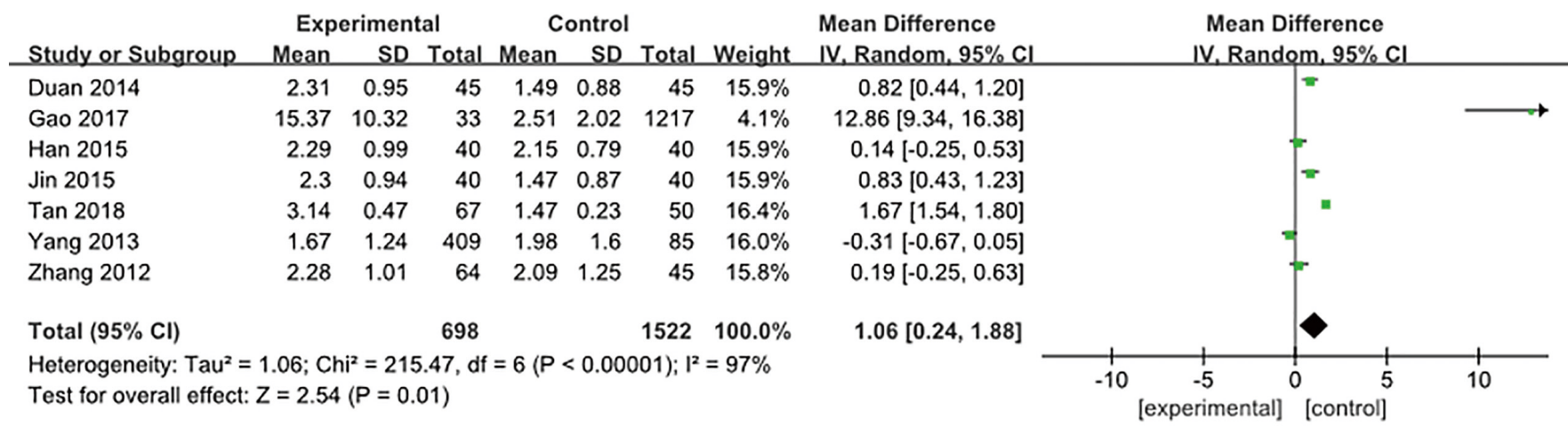

Figure 7 Forest plot of TSH of the two groups of subjects. TSH, thyroid-stimulating hormone.

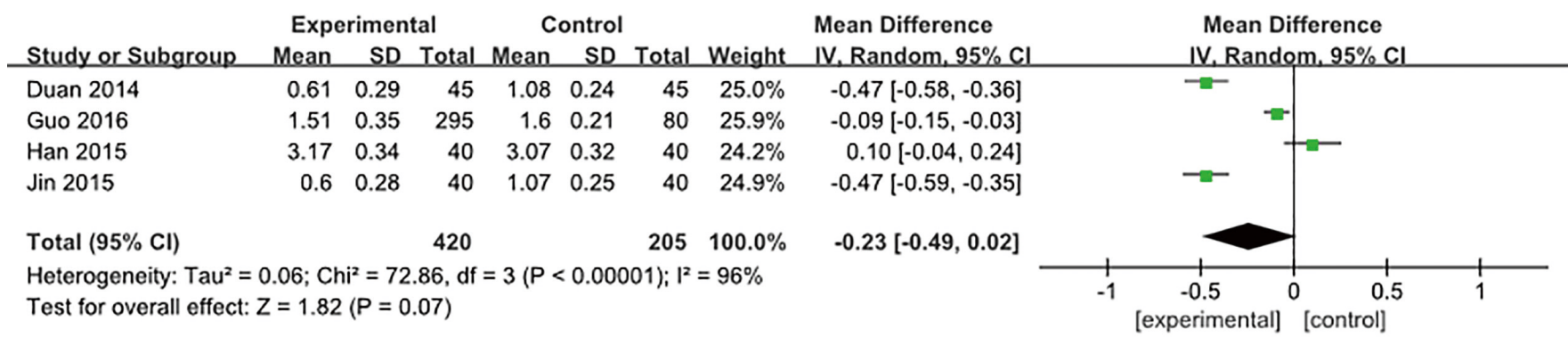

Figure 8 Forest plot of T3 of the two groups. T3, triiodothyronine.

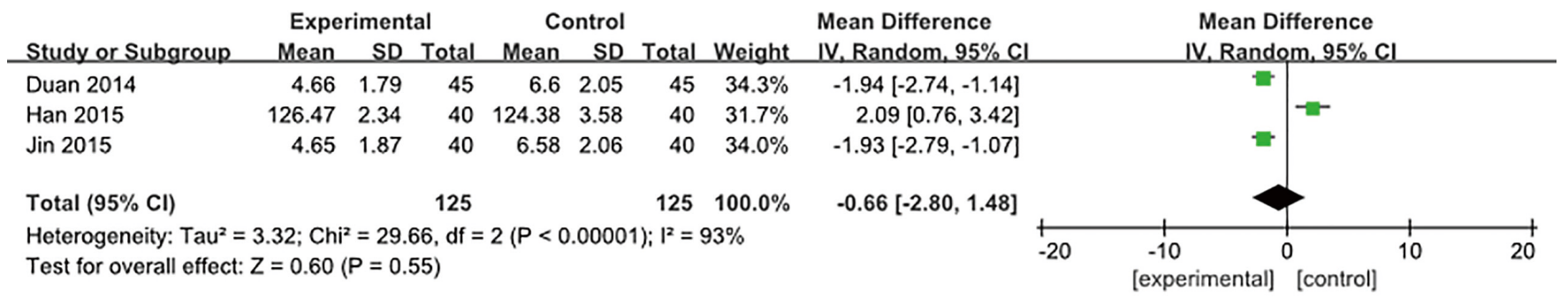

Figure 9 Forest plot of T4 of the two groups. T4, thyroxine.

patients with DN, including 250 subjects with 125 in observation groups and 125 in control groups. As there was heterogeneity between the two groups $\left(\mathrm{I}^{2}=93 \%, \mathrm{P}<0.00001\right)$ the REM was adopted for analysis. Figure 9 shows the combined effect size obtained by meta-analysis is MD $=-0.66,95 \%$ CI: -2.8 to $1.48, Z=0.60$, and $P=0.55$. The diamond in the forest plot is on the left side of the vertical line, which indicates that the T4 level of DN patients is inferior to that of the control group.
Publication bias analysis

Review Manager 5.3 was employed to analyze the publication bias of the analysis indicators of the TCM treatment of DN, and a funnel chart was made, as shown in Figure 10. The FT3 and T3 levels of patients are basically distributed within the credible interval, and the literature bias is small. The scatters representing the literature in the scatter plots of HbAIC, FT4, TSH, and T4 are diffuse, and some of the scatters fall outside the CI. Therefore, there is 

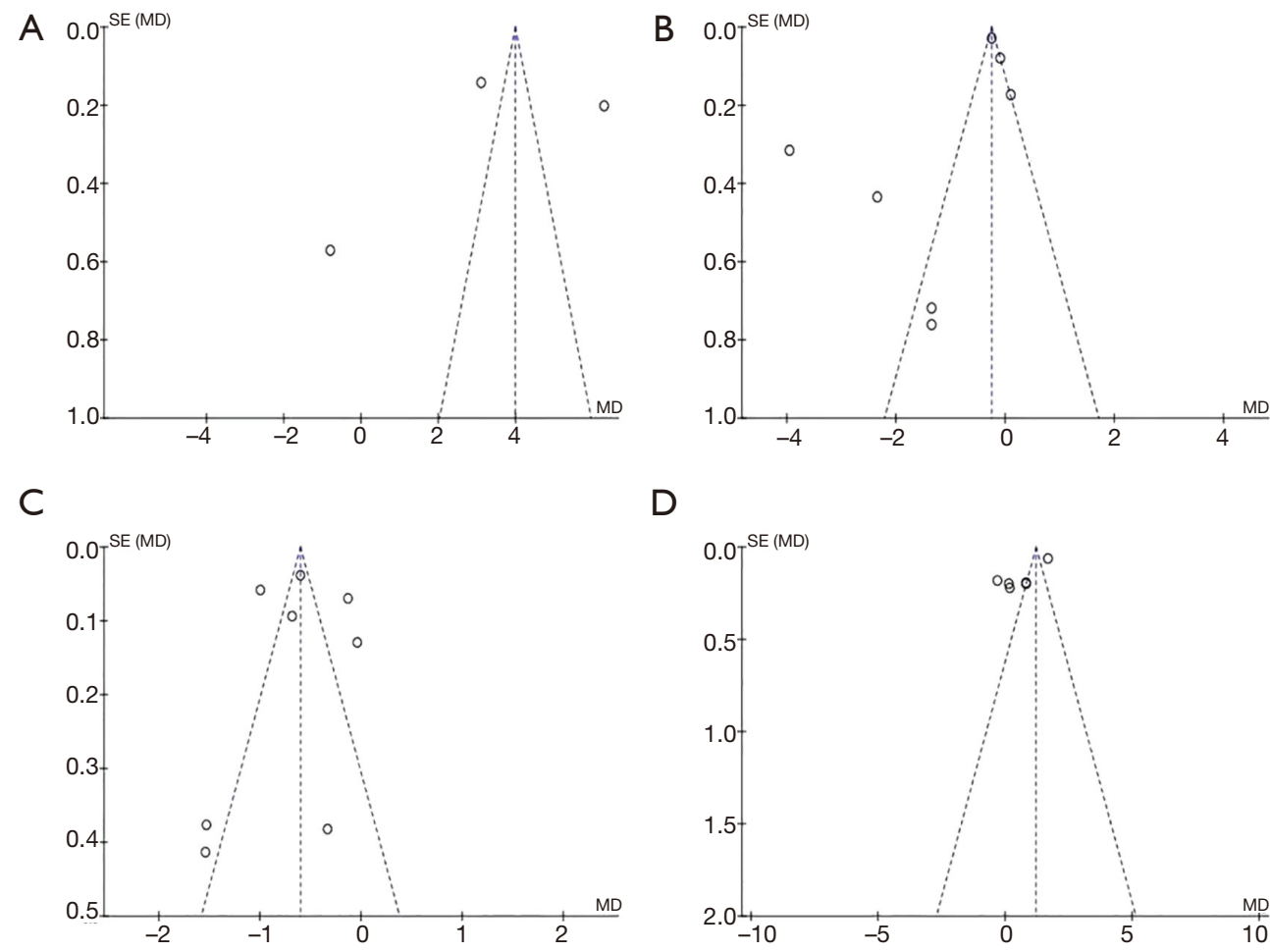

D
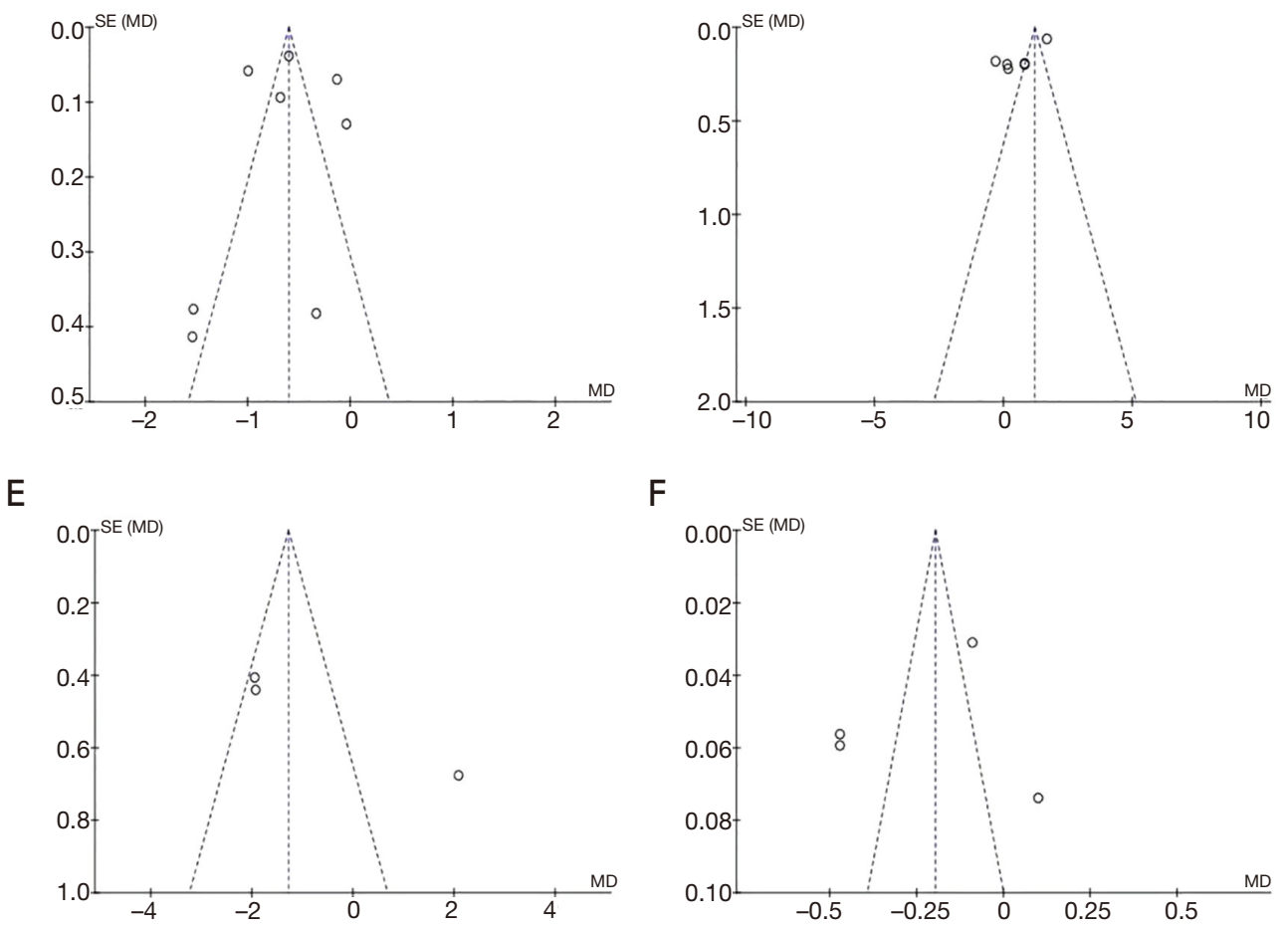

Figure 10 Funnel chart of various outcome evaluation indicators of thyroid function in patients with DN. (A) HbAIC; (B) FT3; (C) FT4; (D) TSH; (E) T3; (F) T4. DN, diabetic nephropathy; HbAIC, glycosylated hemoglobin; FT3, free triiodothyronine; FT4, free thyroxine; TSH, thyroid-stimulating hormone; T3, triiodothyronine; T4, thyroxine.

a certain bias in the included articles.

\section{Meta-analysis of TCM intervention in the treatment of DN}

\section{Literature search results}

The corresponding keywords were searched in the six English databases, and a total of 1,591 related articles were retrieved from the preliminary search (Figure 11). Among these, there were 328 from PubMed, 238 from
Embase, 339 from Medline, 217 from Spring, 189 from Cochrane Library, and 280 from Web of Science. After the preliminary search, Endnote X8 was employed to eliminate duplicates, leaving 1,027 articles. The two evaluators then read the titles and abstracts and excluded 886 articles which obviously did not meet the inclusion criteria. The remaining 141 articles were carefully read and crosschecked by the two evaluators, leaving 12 which met all the inclusion criteria. The twelve articles involved a total of 971 study subjects, including 492 patients in observation groups 


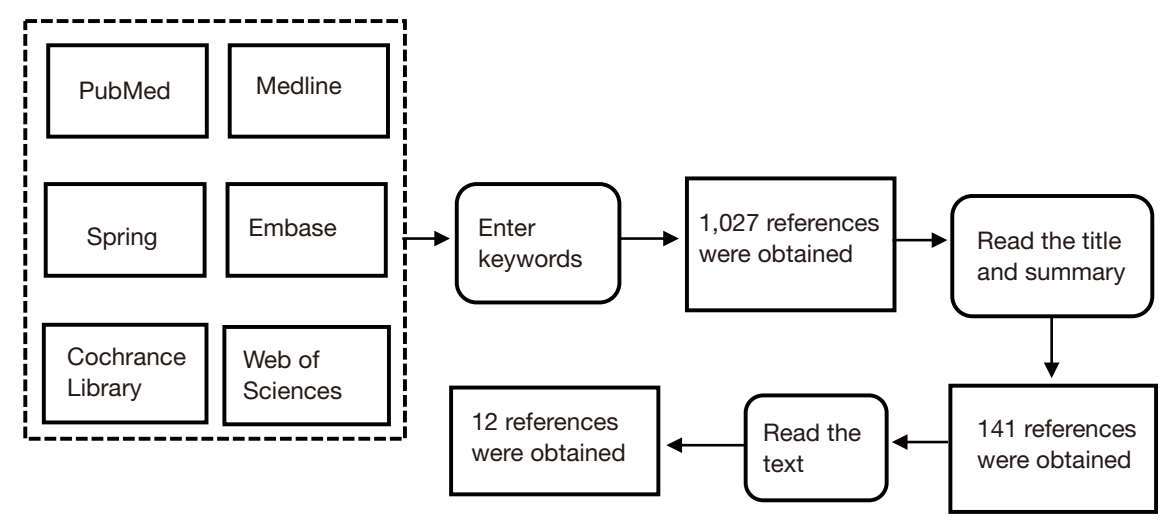

Figure 11 Literature retrieval process.

and 479 in control groups. The details of RCTs in the DN studies involved are shown in Table 2.

\section{Results of literature risk of bias evaluation}

The Cochrane Handbook 5.0.2 bias risk assessment tool was employed to evaluate the bias risk of the twelve articles included in this study, and the evaluation results were input into the Review Manager 5.3 to generate a bias risk map. (I) Random sequence generation. Among the twelve articles, all reported the use of random grouping. Three articles $(21,22,23)$ described specific stochastic methods, indicating low risk, and while six $(13-15,17,18,20)$ mentioned random grouping, the specific random method was not elucidated, indicating unclear risk. The other three articles $(16,17,24)$ did not mention the grouping method, indicating unclear risk. (II) Allocation concealment. Twelve articles (13-24) did not clarify whether blinding was used, and were judged as unclear risk. (III) Subjects blinding. Two articles $(13,22)$ clearly mentioned "patients signed the informed consent forms", but did not mention whether trial staff were blinded, suggesting high risk. The other ten articles $(14-21,23,24)$ did not mention whether the subjects were blinded, suggesting unclear risk. (IV) Blinding of outcome assessor. All twelve articles reported whether the outcome assessment was blinded, suggesting unclear risk. (V) Data integrity. The outcome data of all twelve articles were complete, suggesting low risk. (VI) Selective report. It was impossible to determine whether the twelve articles were selective reports, and the risk was not clear. (VII) Other biases. Four articles $(16,20,23,24)$ had different numbers of subjects in the experimental and control groups, indicating a high risk, while it was uncertain whether there were biases in the other eight articles (13-15,17-19,21,22), suggesting unclear risk. The detailed results of this bias analysis are shown in Figures 12 and 13.

\section{Effective rate of clinical treatment}

Nine $(13,14,16-19,22-24)$ of the twelve articles included in this study reported on the effective rate of clinical treatment of DN by TCM. Among which, a total of 698 subjects were included, including 356 in observation groups and 342 in control groups. As heterogeneity between the two groups was small $\left(\mathrm{I}^{2}=0 \%, \mathrm{P}=0.96\right)$, the FEM was used for analysis. Figure 14 shows that the combined effect size obtained by the meta-analysis was $\mathrm{MD}=6.22,95 \%$ CI: $3.77-10.25$, $Z=7.17$, and $\mathrm{P}<0.00001$. This shows that the treatment of DN with TCM resulted in a substantial difference in clinical treatment efficiency between the observation group and control group, suggesting that the therapeutic effect of TCM intervention in the treatment of $\mathrm{DN}$ is better than conventional Western medicine.

\section{Scr}

Nine $(13,15,17-19,21-24)$ of the twelve articles reported on the Scr of TCM treatment of DN. This involved a total of 757 cases including 379 cases in observation groups and 378 cases in control groups. As heterogeneity between the groups was small $\left(\mathrm{I}^{2}=38 \%, \mathrm{P}=0.12\right)$, the $\mathrm{FEM}$ was used for analysis. Figure 15 shows that the combined effect size obtained by the meta-analysis was $M D=-8.69,95 \%$ CI: -9.92 to $-7.47, Z=13.94$, and $\mathrm{P}<0.00001$. This indicates that there is a remarkable difference in Scr between the observation group and control group after the treatment of $\mathrm{DN}$ with TCM, suggesting that the treatment of DN with TCM can greatly reduce the level of Scr.

\section{BUN}

Nine $(13,15,17-19,21-24)$ of the twelve articles reported 
Table 2 Details of the randomized controlled trials in the diabetic nephropathy (DN) studies involved

\begin{tabular}{|c|c|c|c|c|c|}
\hline $\begin{array}{l}\text { The first } \\
\text { author }\end{array}$ & $\begin{array}{l}\text { Published } \\
\text { year }\end{array}$ & Group & $\begin{array}{l}\text { Sample } \\
\text { size }\end{array}$ & Gender & Intervention \\
\hline Zhao Y (13) & 2019 & Experimental & 45 & $27+18$ & Integrated traditional Chinese and Western Medicine \\
\hline Dong JH (14) & 2010 & Experimental & 50 & - & Integrated traditional Chinese and Western Medicine \\
\hline Yu BH (15) & & Control & 26 & o17; +9 & Conventional Western Medicine \\
\hline \multirow[t]{2}{*}{ Ma WG (16) } & 2012 & Experimental & 33 & ô19; +14 & Integrated traditional Chinese and Western Medicine \\
\hline & & Control & 30 & J16; 우14 & Conventional Western Medicine \\
\hline Zhao RF (18) & & Control & 49 & 26; +23 & Conventional Western Medicine \\
\hline \multirow[t]{2}{*}{ Zhu J (19) } & 2017 & Experimental & 30 & - & TCM Treatment \\
\hline & & Control & 30 & - & Conventional Western Medicine \\
\hline \multirow[t]{2}{*}{ Fang H (20) } & 2017 & Experimental & 30 & - & Integrated traditional Chinese and Western Medicine \\
\hline & & Control & 31 & - & Conventional Western Medicine \\
\hline \multirow[t]{2}{*}{ Si TL (21) } & 2015 & Experimental & 80 & $44 ; 936$ & Integrated traditional Chinese and Western Medicine \\
\hline & & Control & 80 & $46 ;$ & Conventional Western Medicine \\
\hline Yi N (24) & & Control & 30 & - & Conventional Western Medicine \\
\hline
\end{tabular}

on BUN in the treatment of DN by TCM. This involved 757 cases, including 379 cases in observation groups and 378 cases in control groups. As heterogeneity between the groups was found $\left(\mathrm{I}^{2}=88 \%, \mathrm{P}<0.00001\right)$, the $\mathrm{REM}$ was adopted for analysis. Figure 16 shows that the combined effect size obtained by the meta-analysis was $\mathrm{MD}=-1.74$, $95 \%$ CI: -2.48 to $-1.00, Z=4.60$, and $\mathrm{P}<0.00001$. The diamond in the forest plot is on the left side of the vertical line, which indicates that the postoperative BUN level of patients with DN treated by TCM is inferior to that of the control group.

\section{UAER}

Five $(13,18-20,24)$ of the twelve articles reported on the UAER of TCM for DN. Among these, 369 subjects were included, including 184 in observation groups and 185 in control groups. As there was heterogeneity between the groups $\left(\mathrm{I}^{2}=99 \%, \mathrm{P}<0.00001\right)$, the REM was adopted for analysis. Figure 17 shows that the combined effect size obtained by the meta-analysis was $M D=-26.16,95 \%$ CI: -46.89 to $-5.44, Z=2.47$, and $\mathrm{P}=0.01$. The diamond in the forest plot is located on the left side of the vertical line, which suggests that the postoperative UAER level of patients with 


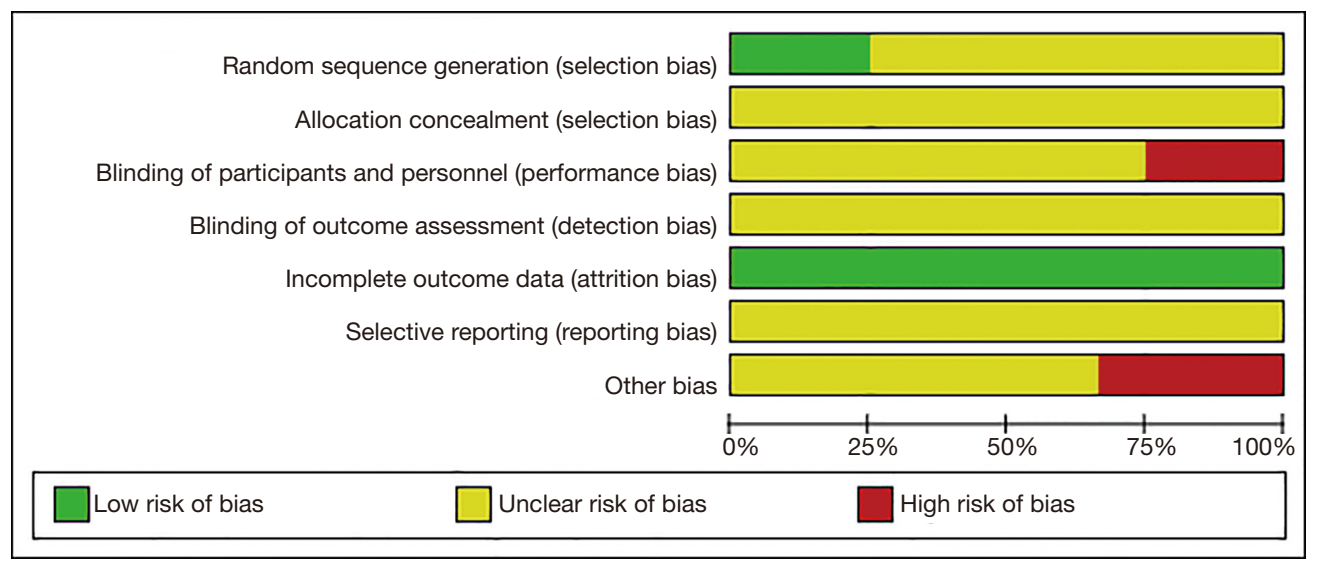

Figure 12 Bar graph of bias analysis of included literatures.

\begin{tabular}{|c|c|c|c|c|c|c|c|c|c|c|c|c|}
\hline $\begin{array}{l}\text { N } \\
\text { ᄃ } \\
\text { N } \\
\text { ․ } \\
\text { V }\end{array}$ & 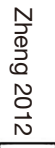 & 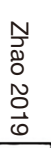 & $\begin{array}{l}\text { No } \\
\text { Oొ } \\
\text { N } \\
8 \\
0\end{array}$ & 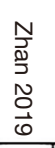 & $\begin{array}{l}\text { న } \\
\stackrel{0}{J} \\
\text { N } \\
\stackrel{0}{0} \\
\text { a }\end{array}$ & 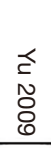 & $\begin{array}{l}\leq \\
N \\
0 \\
\sigma \\
\end{array}$ & 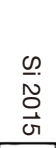 & $\begin{array}{l}3 \\
\mathbb{N} \\
N \\
\frac{0}{N} \\
N\end{array}$ & 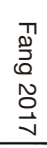 & 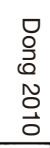 & \\
\hline$\sim$ & $\sim$ & $\sim$ & $\sim$ & + & + & $\sim$ & $\sim$ & + & $\sim$ & $\sim$ & $\sim$ & Random sequence generation (selection bias) \\
\hline$\sim$ & $\sim$ & $\sim$ & $\sim$ & $\sim$ & $\sim$ & $\sim$ & $\sim$ & $\sim$ & $\sim$ & $\sim$ & $\sim$ & Allocation concealment (selection bias) \\
\hline$\sim$ & $\sim$ & (1) & $\sim$ & (1) & $\sim$ & $\sim$ & $\sim$ & $\sim$ & $\sim$ & $\sim$ & (1) & Blinding of participants and personnel (performance bias) \\
\hline$\sim$ & $\sim$ & $\sim$ & $\sim$ & $\sim$ & $\sim$ & $\sim$ & $\sim$ & $\sim$ & $\sim$ & $\sim$ & $\sim$ & Blinding of outcome assessment (detection bias) \\
\hline+ & + & $\odot$ & + & + & + & + & + & + & + & + & + & Incomplete outcome data (attrition bias) \\
\hline$\sim$ & $\sim$ & $\sim$ & $\sim$ & $\sim$ & $\sim$ & $\sim$ & $\sim$ & $\sim$ & $\sim$ & $\sim$ & $\omega$ & Selective reporting (reporting bias) \\
\hline$\sim$ & $\sim$ & $\sim$ & $\sim$ & $\sim$ & (1) & $\sim$ & (1) & $\sim$ & 0 & $\sim$ & 8 & Other bias \\
\hline
\end{tabular}

Figure 13 Bias risk assessment diagram of included articles.

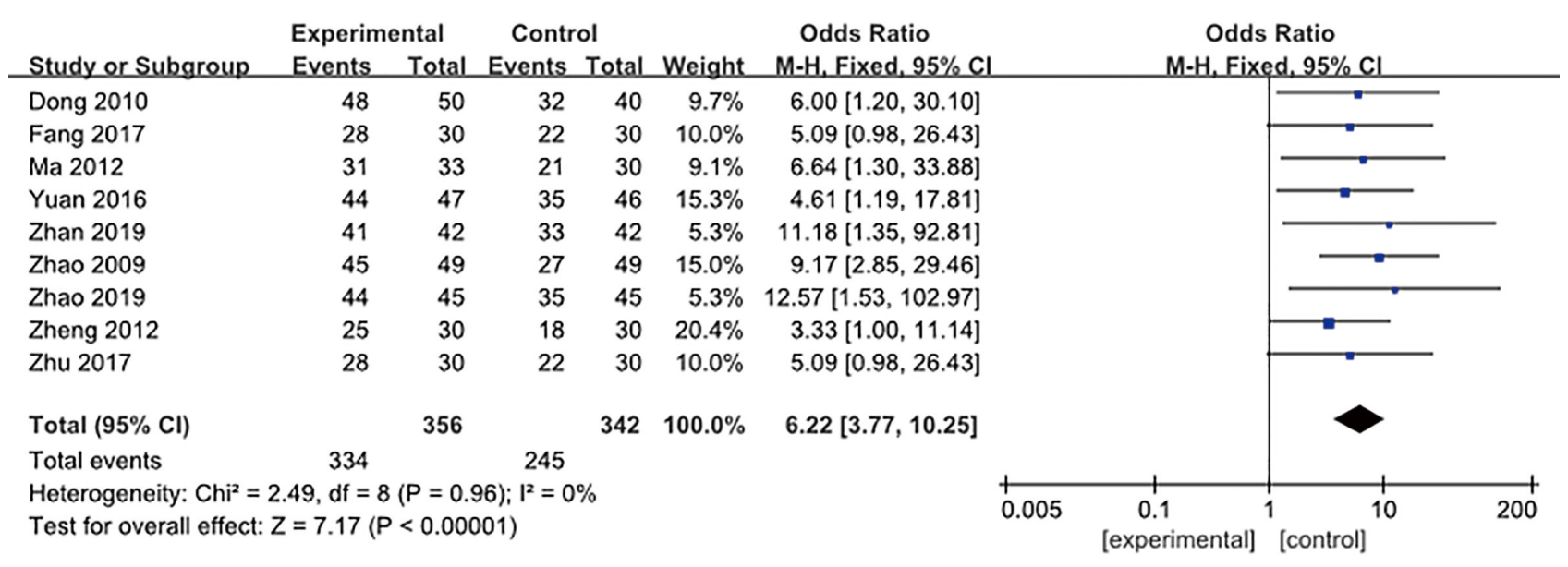

Figure 14 Forest plot of the effective rate of clinical treatment of the two groups. 


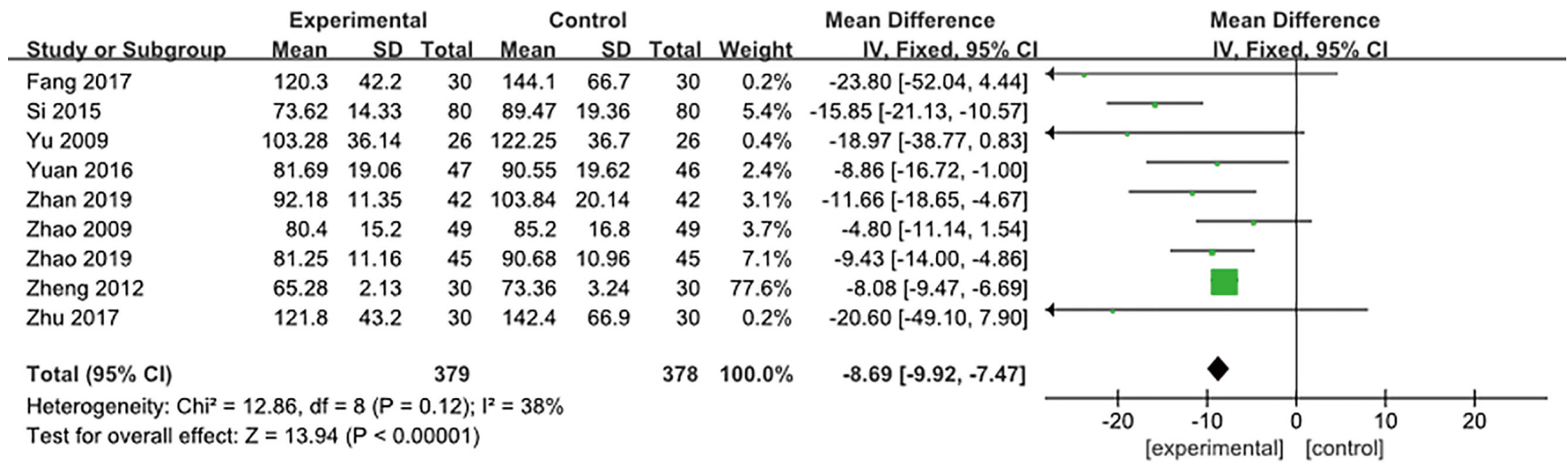

Figure 15 Forest plot of serum creatinine in the two groups.

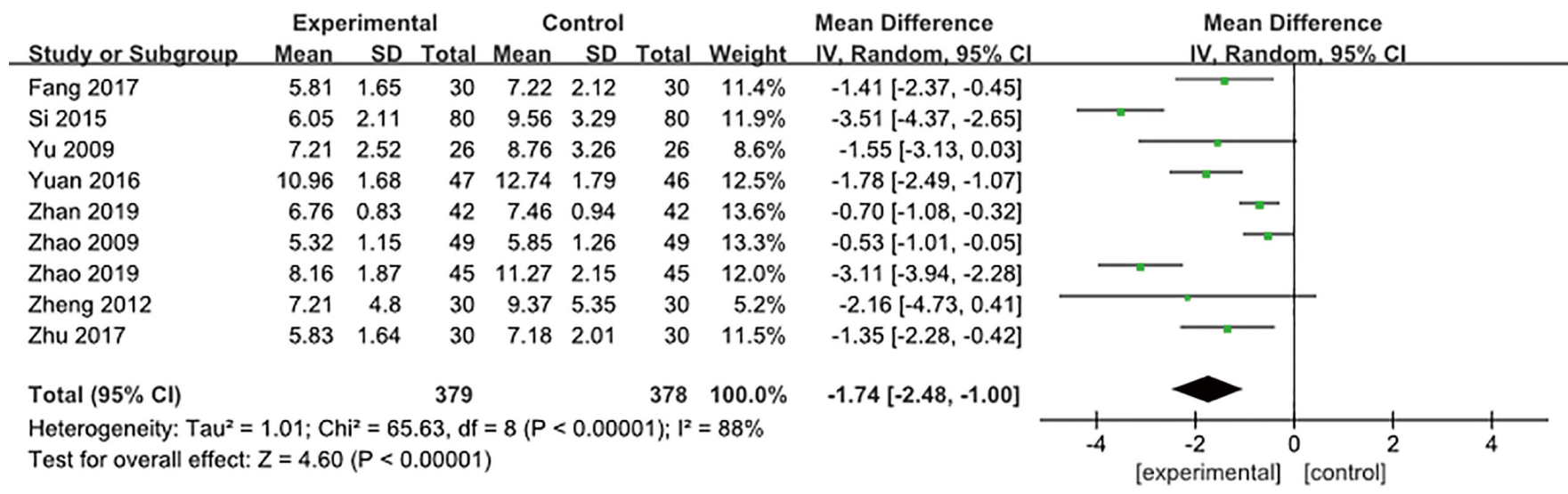

Figure 16 Forest plot of urea nitrogen in the two groups.

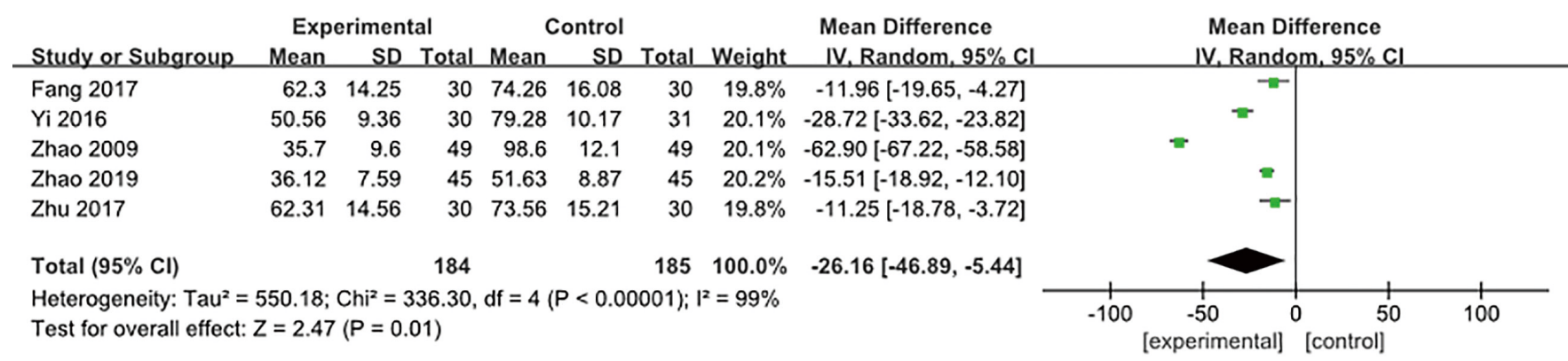

Figure 17 Forest plot of UAER of two groups. UAER, urine protein excretion rate.

DN treated by TCM is inferior to that of the control group.

Twenty-four hours postoperative urine protein quantitation

Four $(15,17,19,24)$ of the twelve articles reported on the
$24 \mathrm{~h}$ postoperative urine protein quantitation of TCM in the treatment of DN. A total of 232 cases were included, including 116 cases in observation groups and 116 cases in control groups. As heterogeneity was found between the two groups, $\left(\mathrm{I}^{2}=59 \%, \mathrm{P}=0.06\right)$, the REM was adopted 


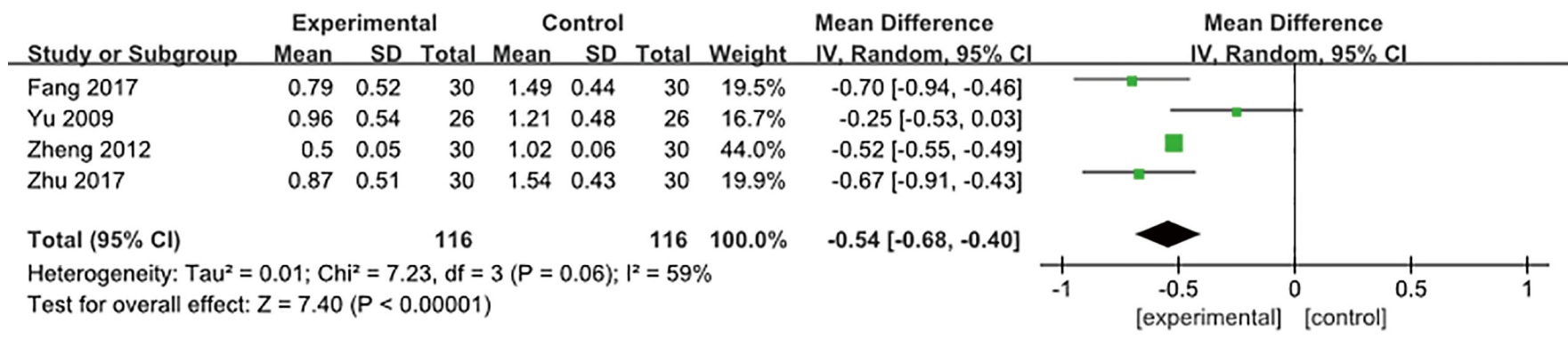

Figure 18 Forest plot of $24 \mathrm{~h}$ postoperative urine protein quantitation of two groups.

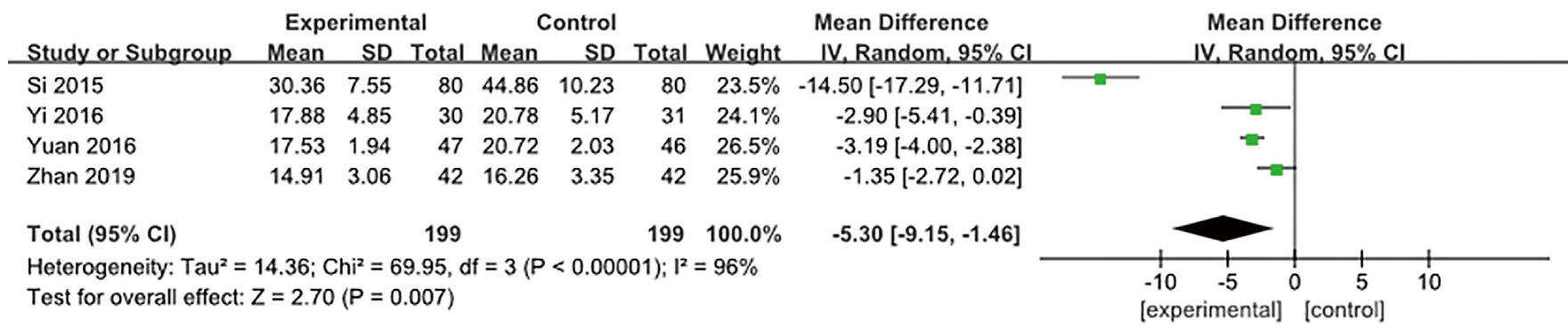

Figure 19 Forest plot of TNF- $\alpha$ of the two groups. TNF- $\alpha$, tumor necrosis factor-alpha.

for analysis. Figure 18 shows that the combined effect size obtained by the meta-analysis was $\mathrm{MD}=-0.54,95 \% \mathrm{CI}$ : -0.68 to $-0.40, Z=7.40$, and $\mathrm{P}<0.00001$. The diamond in the forest plot is on the left side of the vertical line, which suggests that the $24 \mathrm{~h}$ postoperative urine protein quantitative level of patients with DN treated by TCM is inferior to that of the control group.

\section{TNF- $\alpha$}

Four (20-23) of the twelve articles reported on TNF- $\alpha$ in the treatment of DN by TCM with a total of 398 subjects, including 199 in observation groups and 199 in control groups. As heterogeneity between the groups $\left(\mathrm{I}^{2}=96 \%\right.$, $\mathrm{P}<0.00001)$ was found, the REM was adopted for analysis. Figure 19 shows that the combined effect size obtained by the meta-analysis was $\mathrm{MD}=-5.30,95 \% \mathrm{CI}:-9.15$ to -1.46 , $Z=2.70$, and $P=0.007$. The diamond in the forest plot is on the left side of the vertical line, which indicates that the postoperative TNF- $\alpha$ level of patients with DN treated by TCM is inferior to that of the control group.

\section{hs-CRP}

Three of the twelve articles (21-23) reported on hs-CRP in the treatment of DN by TCM. Of these, 337 cases were included in the study, including 169 cases in observation groups and 168 cases in control groups, and analysis showed heterogeneity between the two groups $\left(\mathrm{I}^{2}=90 \%\right.$, $\mathrm{P}<0.00001)$. Therefore, the REM was adopted for analysis. Figure 20 shows that the combined effect size obtained by the meta-analysis was $\mathrm{MD}=-1.34,95 \% \mathrm{CI}:-1.90$ to -0.78 , $Z=4.66$, and $\mathrm{P}<0.00001$. The diamond in the forest plot is on the left side of the vertical line, which suggests that the postoperative hs-CRP level of patients with DN treated by TCM is inferior to that of the control group.

\section{Publication bias analysis}

Review Manager 5.3 was employed to analyze the publication bias of the analysis indicators of the TCM treatment of DN, and a funnel chart was made, as shown in Figure 21. The clinical effective rate, Scr, BUN levels, and UAER levels are basically distributed within the credible interval, and literature bias is small. The scatters representing the literature in the scatter plots of $24 \mathrm{~h}$ urine protein quantification, TNF- $\alpha$, and hs-CRP are diffuse, and some of the scatters fall outside the CI. Therefore, there is a certain bias in the included articles. 


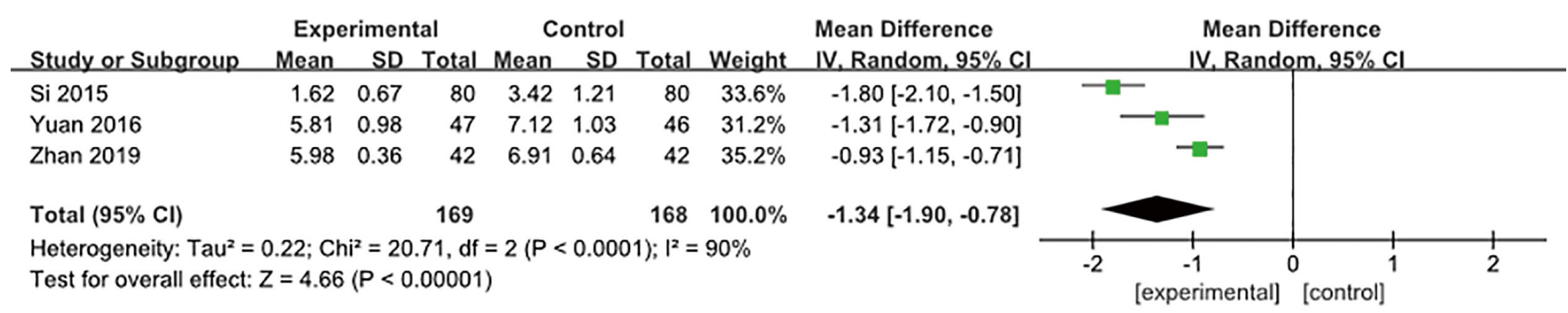

Figure 20 Forest plot of hs-CRP of the two groups. hs-CRP, high sensitivity C-reactive protein.
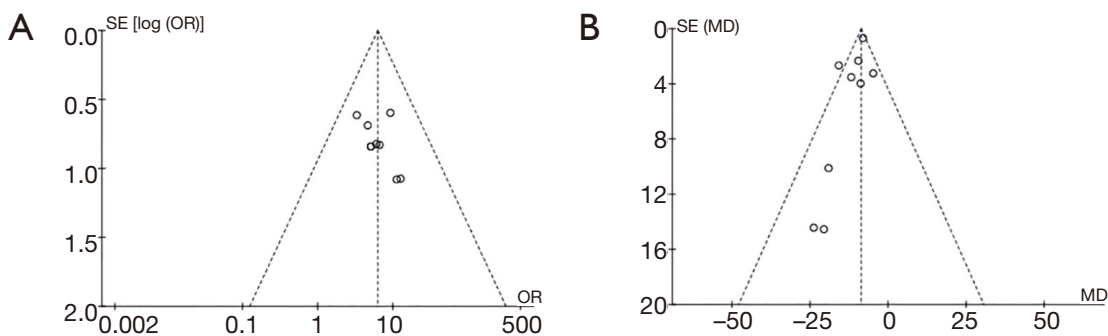

C

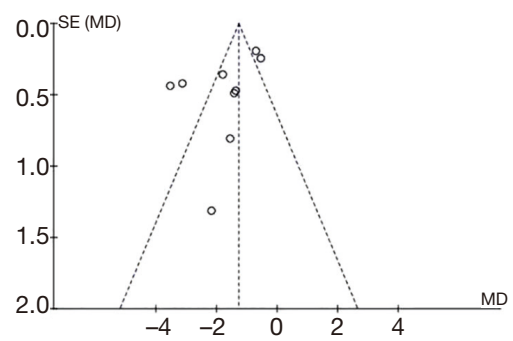

D $0.000^{\mathrm{SE}}(\mathrm{MD})$

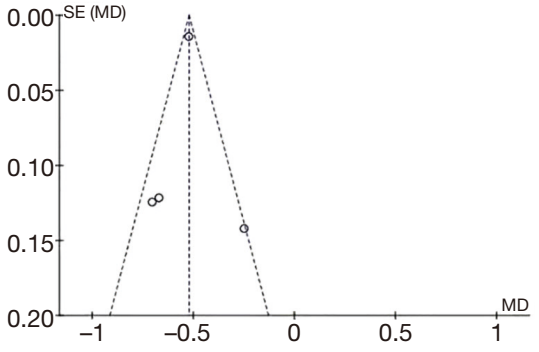

$E$

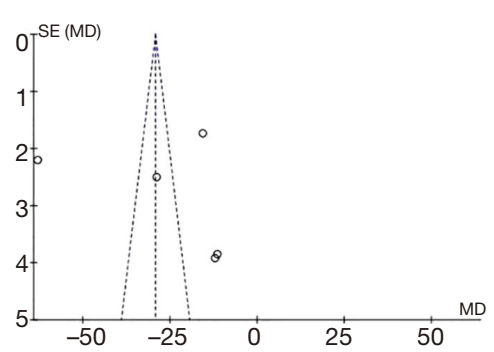

G

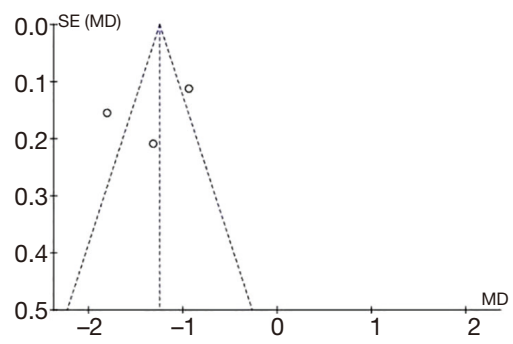

$\mathrm{F}$

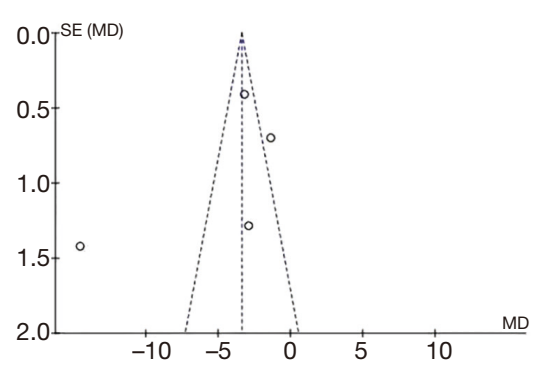

Figure 21 Funnel chart of various outcome evaluation indicators for TCM treatment of DN. (A) Clinical effective rate; (B) Scr; (C) BUN; (D) UAER; (E) 24 h postoperative urine protein quantification; (F) TNF- $\alpha$; (G) hs-CRP. TCM, traditional Chinese medicine; DN, diabetic nephropathy; Scr, serum creatinine; BUN, blood urea nitrogen; UAER, urine protein excretion rate; TNF- $\alpha$, tumor necrosis factor-alpha; hs-CRP, high sensitivity C-reactive protein. 


\section{Discussion}

The main pathological features of DN are glomerular hypertrophy and tubular basement membrane thickening (25), which are caused by improper control of diabetes and severe abnormalities of insulin and thyroid function. Importantly, although the disease is reversible, as $\mathrm{DN}$ progresses slowly, its clinical manifestations may go unnoticed, and deterioration of the condition can occur if the patient is not treated in a timely manner (26). Through the statistical analysis of thyroid function, we found that the levels of FT3, FT4, T3, and T4 in patients with DN are inferior to those in a control group, while the TSH levels are higher than those in the control group, suggesting that the thyroid function of patients with $\mathrm{DN}$ is impaired to varying degrees.

The current clinical treatment of DN involves blood glucose and blood pressure control, but the treatment results are slow and not optimal (27). TCM practitioners believe DN is "kidney elimination", and secondary to diabetes "urine turbidities", "edema", "fullness", and "obstruction and rejection". The disease starts in the kidney, often involves the liver, spleen, and lung, and in the later stage involves the heart and disease of all five viscera (28). In the early stage, the deficiency of both Qi and Yin is dominant, and in the late stage, all Qi, blood, Yin, and Yang are deficient, and turbidity and toxicity are retained (29). Finally, the nephron deteriorates, and all the five visceral organs are injured. Therefore, TCM treatment should mainly be "nourishing qi and nourishing Yin, as well as nourishing liver and kidney" (30). To accurately evaluate the clinical efficacy of TCM intervention in the treatment of $\mathrm{DN}$, a meta-analysis was performed to research and analyze the twelve included articles, and the results showed that the clinical efficacy of TCM intervention in the treatment of patients with $\mathrm{DN}$ is significant. In addition, Scr, BUN, UAER, 24h postoperative urine protein quantification, TNF- $\alpha$, and hs-CRP levels were inferior to those of the control group. This suggests TCM intervention in the treatment of $\mathrm{DN}$ is effective to relieve the clinical symptoms of the patients, which also alleviates the condition and has an ideal therapeutic effect.

\section{Conclusions}

A meta-analysis conducted to evaluate the thyroid function of patients with DN found that it was impaired to varying degrees. Analysis of the clinical efficacy of
TCM intervention in the treatment of $\mathrm{DN}$ showed that TCM could effectively improve the clinical symptoms of patients and improve the treatment effect. However, due to the small sample size, only the curative effect after the treatment was analyzed, and the long-term efficacy of TCM intervention in the treatment of DN remains unknown. Follow-up research of a higher quality involving larger samples, and multi-center RCT trials should be carried out to supplement the deficiencies of this research, and more accurately evaluate the clinical efficacy of TCM intervention in the treatment of $\mathrm{DN}$.

\section{Acknowledgments}

Funding: This study was kindly approved by 2020 Sichuan Science and Technology Program Project (2020 YFS0384).

\section{Footnote}

Reporting Checklist: The authors have completed the PRISMA reporting checklist. Available at http://dx.doi. org/10.21037/apm-21-1220

Conflicts of Interest: All authors have completed the ICMJE uniform disclosure form (available at http://dx.doi. org/10.21037/apm-21-1220). The authors have no conflicts of interest to declare.

Ethical Statement: The authors are accountable for all aspects of the work in ensuring that questions related to the accuracy or integrity of any part of the work are appropriately investigated and resolved.

Open Access Statement: This is an Open Access article distributed in accordance with the Creative Commons Attribution-NonCommercial-NoDerivs 4.0 International License (CC BY-NC-ND 4.0), which permits the noncommercial replication and distribution of the article with the strict proviso that no changes or edits are made and the original work is properly cited (including links to both the formal publication through the relevant DOI and the license). See: https://creativecommons.org/licenses/by-nc-nd/4.0/.

\section{References}

1. Ioannou K. Diabetic nephropathy: is it always there? Assumptions, weaknesses and pitfalls in the diagnosis. Hormones (Athens) 2017;16:351-61. 
2. Furuichi K, Shimizu M, Hara A, et al. Diabetic Nephropathy: A Comparison of the Clinical and Pathological Features between the CKD Risk Classification and the Classification of Diabetic Nephropathy 2014 in Japan. Intern Med 2018;57:3345-50.

3. Van JA, Scholey JW, Konvalinka A. Insights into Diabetic Kidney Disease Using Urinary Proteomics and Bioinformatics. J Am Soc Nephrol 2017;28:1050-61.

4. Elmarakby AA, Sullivan JC. Relationship between oxidative stress and inflammatory cytokines in diabetic nephropathy. Cardiovasc Ther 2012;30:49-59.

5. Zhang L, Du Q. A Research on the change and correlations of senlln thyroid horm one levels in patients winl diabetic nephrop- athy IVG Lin. China Medicine 2012:7:428-30.

6. Han J, Xu J, Cao N, et al. Clinical analysis of thyroid autoantibody and function of type 2 diabetic nephropathy patients. International Journal of Pathology and Clinical Medicine 2015:35:2102-7.

7. Jin JH, Hong $\mathrm{YZ}, \mathrm{Xu} \mathrm{XP}$, et al. The correlation analysis between type 2 diabetic nephropathy severity and thyroid function. Chinese Journal of Primary Medicine and Pharmacy 2015:22:967-9.

8. Gao HB, Zhang YW, Xie YL, et al. Study on the Relationship between Subclinical Hypothyroidism and Type 2 Diabetic Nephropathy. Medical Information 2017:30:33-4.

9. Tan ZM, Zhang Y, Teng YJ, et al. Correlation between Serum Thyroid Hormone Levels in Patients with Diabetic Kidney Disease and Subclinical Hypothyroidism. Journal of Modern Laboratory Medicine 2018;33:95-8.

10. Duan SL. Analysis of the correlation between type 2 diabetic nephropathy severity and thyroid function. Journal of Clinical Medical Literature (Electronic Edition) 2014;1:1437,1439.

11. Yang N, Xu Y, Wang G, et al. Correlation analysis between metabolism indices and thyroid function parameters in patients with type 2 diabetic mellitus. China Medical Herald 2013;10:64-6,71.

12. Guo F, Gao YH. Analysis of Biochemical and Thyroid Function Indicators in Patients with Type 2 Diabetes. Labeled Immunoassays and Clinical Medicine 2016;23:119-22.

13. Zhao Y. Effect of combined therapy of Chinese and Western medicine for early diabetic nephropathy. Contemporary Medicine Forum 2019;17:2-4.

14. Dong JH, Chu CZ. Clinical Analysis of Combining Chinese and Western Medicine Treatment of Diabetic
Nephropathy. Journal of Anhui Health Vocational \& Technical College 2010;9:34-5.

15. Yu BH, Zhang ZH. Chinese Medicine Tonifying Qi Kidney and Activating Blood Circulation Treat Diabetic Nephropathy (DN). Journal of Zhejiang University Of Traditional Chinese Medicine 2009;33:184-5.

16. Ma WG. Clinical examination on treating 63 cases of diabetic nephropathy. Clinical Journal of Chinese Medicine 2012;04:21-2.

17. Zheng HG, Li XL, Li XF, et al. Observation of Yiqi Wenyang Jiangzhuo Chinese herbal medicine on diabetic nephropathy. Hebei Journal of Traditional Chinese Medicine 2012;34:1787-9.

18. Zhao RF, Wang CP, Shu BM, et al. Clinical Curative Effect of Traditional Chinese Medicine Combined with Benazepril in Treatment of Diabetic Nephropathy and Its Impact on Renal Function. Practical Preventive Medicine 2009;16:1181-3.

19. Zhu J. Clinical Effect of Chinese Medicine on Diabetic Nephropathy. China Health Standard Management 2017;8:106-7.

20. Fang H, Hang J, Cui Y. To Investigate the Clinical Effect of Chinese Medicine in the Treatment of Diabetic Nephropathy. China Continuing Medical Education 2017;9:192-4.

21. Si TL. Impact of Wenyanghuatan treatment on inflammatory factors in patients with diabetic nephropathy. Chinese Journal of General Practice 2015;13:1341-3.

22. Zhan FF. Effect of Bailing Capsulesin Adjuvant Treatment of Patients with Diabetic Nephropathy on Curative Effect, Renal Function and Micro-inflammatory State. Journal of New Chinese Medicine 2020;52:56-9.

23. Yuan F. Effect of Diabetic Kidney Qi and Spleen Inflammatory Cytokines and Renal Function in Patients with Kidney Disease. Systems Medicine and Pharmacology 2016;1:20-2.

24. Yi N, Chen LL, Li HZ. Efficacy of Qidan Yin on inflammatory factor and renal function in EDN. Clinical Journal of Chinese Medicine 2016:19:28-30.

25. Churilov LP, Sobolevskaia PA, Stroev YI. Thyroid gland and brain: Enigma of Hashimoto's encephalopathy. Best Pract Res Clin Endocrinol Metab 2019;33:101364.

26. Stagnaro-Green A, Abalovich M, Alexander E, et al. Guidelines of the American Thyroid Association for the diagnosis and management of thyroid disease during pregnancy and postpartum. Thyroid 2011;21:1081-125.

27. Zhang K, Wang Y, Ma W, et al. Genistein improves thyroid function in Hashimoto's thyroiditis patients 
through regulating Th1 cytokines. Immunobiology 2017;222:183-7.

28. Bakırtaş Palabıyık F, İnci E, Papatya Çakır ED, et al. Evaluation of Normal Thyroid Tissue and Autoimmune Thyroiditis in Children Using Shear Wave Elastography. J Clin Res Pediatr Endocrinol 2019;11:132-9.

29. Bakhshandeh M, Hashemi B, Mahdavi SR, et al. Evaluation of thyroid disorders during head-and-neck radiotherapy by using functional analysis and ultrasonography. Int J Radiat Oncol Biol Phys 2012;83:198-203.

30. Peng X, Wu S, Bie C, et al. Mean peak systolic velocity of superior thyroid artery for the differential diagnosis of thyrotoxicosis: a diagnostic meta-analysis. BMC Endocr Disord 2019;19:56.

(English Language Editor: B. Draper)

Cite this article as: Zhang $\mathrm{X}, \mathrm{Wu} \mathrm{M}$, Zhou J, Zhou R, Luo Q, Yue R, Jin S. Meta-analysis-based systematic review of effect of traditional Chinese medicine intervention in treatment of diabetic nephropathy on thyroid function. Ann Palliat Med 2021;10(6):6736-6752. doi: 10.21037/apm-21-1220 